\title{
COVID-19 Vaccine Demand and Financial Incentives
}

\author{
Carlos E. Carpio ${ }^{1}$ ] $\cdot$ Ioana A. Coman ${ }^{2} \cdot$ Oscar Sarasty $^{1} \cdot$ Manuel García $^{1}$
}

Accepted: 12 September 2021 / Published online: 5 October 2021

(C) The Author(s), under exclusive licence to Springer Nature Switzerland AG 2021

\begin{abstract}
Background Public health experts estimate that only very high COVID-19 vaccine uptake levels can result in herd immunity. Objective This study's main objective was to evaluate the impact of vaccine price levels, including payments, and the efficacy levels on COVID-19 vaccine demand.

Methods Data for this study were collected from an online survey of 2000 US individuals aged 18 years and older, which included a set of contingent valuation questions. Parametric and nonparametric procedures were used to estimate the distribution of willingness-to-pay and willingness-to-accept values for the vaccine and to assess its association with vaccine efficacy levels (50, 70, and 95\%).

Results Most of the individuals (60\%) indicated they were willing to pay a positive amount for the vaccine; $13.7 \%$ said they would only accept the vaccine if it were free; $14.1 \%$ were willing to take the vaccine only if they were paid; and $12.2 \%$ were not willing to accept the vaccine. The vaccine efficacy level was found to affect an individual's demand for the vaccine. Estimated mean willingness-to-pay values were: US\$594, US\$706, and US\$723 for vaccines with efficacy levels of 50, 70, and $95 \%$, respectively.

Conclusions US individuals highly value the COVID-19 vaccine, and about $88 \%$ of the US population would accept the vaccination; however, $14 \%$ indicated they would get vaccinated if compensated. Payments of about US\$500 or more would be needed to sufficiently incentivize $50 \%$ or more of this group vaccinated.
\end{abstract}

\section{Key Points for Decision Makers}

This study found that about $88 \%$ of the US population would accept the COVID-19 vaccine but $14 \%$ indicated they would get vaccinated only if compensated.

It is estimated that payments of at least US\$525 are needed to sufficiently incentivize $50 \%$ or more of those willing to get vaccinated only if compensated.

As vaccine efficacy levels were also found to affect vaccine demand, vaccines with relatively lower efficacy levels may result in higher vaccine hesitancy.

Carlos E. Carpio

carlos.carpio@ttu.edu

1 Department of Agricultural and Applied Economics, Texas Tech University, Lubbock, TX 79409-2132, USA

2 Department of Public Relations, Texas Tech University, Lubbock, TX, USA

\section{Introduction}

One of the most significant medical accomplishments in 2020 was the successful development in less of a year of a vaccine against the severe acute respiratory syndrome coronavirus 2, the cause of the coronavirus disease 2019 (COVID-19). As of 24 August, 2021, 99 vaccines are now reported in clinical trials on humans, and 20 vaccines have been authorized and approved for use in several countries [1]. However, several challenges remain regarding their deployment, including vaccine manufacturing, distribution, and public acceptance.

Public health experts estimate that only very high COVID-19 vaccine uptake levels (70-90\%) can result in the final objective of reaching the herd immunity needed to return to normal life. Some economists have suggested paying people to get the COVID-19 vaccine to overcome vaccine skepticism and increase its acceptance [2-5]. It is also reported that some employers plan to provide (or are already providing) financial incentives to their employees to increase vaccination rates, including $401(\mathrm{k})$ deposits (i.e., deposits on employer-sponsored pension accounts), cash, and gift cards 
[6]. Paying individuals to get vaccinated can be justified, as vaccination against COVID-19 benefits the individual receiving the vaccine and their community, as broad vaccination decreases the number of hosts for the virus. Still, little is known about the potential effect of financial incentives to increase COVID-19 vaccination rates. Therefore, this study's main objective was to evaluate the impact of vaccine price levels, including payment, on the demand for COVID-19 vaccines. A secondary objective was to assess the effect of vaccine efficacy level information on demand and acceptability.

The economic concept of willingness to pay (WTP) has been used widely to assess individuals' vaccine acceptability and demand [7-11]. Willingness to pay provides a measure of the maximum amount of money an individual is willing to give for acquiring a product or service. Getting vaccinated includes both expected benefits as well as expected costs. Expected benefits include avoiding direct (e.g., medical costs) and indirect expenses (e.g., lost income due to the disease) related to an illness. Expected costs include those associated with acquiring the vaccine (price paid, time spent waiting in line) and costs associated with vaccine potential side effects. Individuals' WTP value for a vaccine can then be interpreted as an individual valuation of the expected net benefits (benefits-costs) provided by a vaccine which, in most cases, are assumed to be positive. However, it is also possible that some individuals' valuation of a vaccine is negative if, for example, they believe a vaccine is unnecessary, has a high price tag, or can result in costly and adverse side effects. Individuals would then need to be compensated for accepting a vaccine. Willingness-to-accept (WTA) values measure the minimum compensation an individual will require to get vaccinated.

Several studies have evaluated individuals' WTP for hypothetical vaccines, including the COVID-19 vaccine [12-18]. There is also a more limited thread of literature assessing the use of financial incentives to promote vaccination [19-22]. This study evaluates vaccine demand and acceptability using a contingent valuation approach that encompasses both WTP and WTA values. The study aims to inform public policy discussion regarding the use of different mechanisms and policies to promote COVID-19 vaccination acceptance.

\section{Methods}

\subsection{Data and Survey Instrument}

Data for this study were collected from a survey of US individuals aged 18 years and older. The survey collected information on individuals' acceptability and knowledge about COVID-19 vaccines, sociodemographic characteristics, and responses to a set of contingent valuation (CV) questions. The CV questions were used to determine: (1) the proportion of individuals' willing to accept vaccination based on their WTP or WTA a payment, and (2) WTP and WTA values for those willing to pay and those willing to get vaccinated when offered a payment, respectively (Fig. 1). Amazon's Mturk was used for the online data collection from a national sample of 2000 individuals in the USA from 24 December, 2020 to 2 January, 2021. A total of 1895 complete observations were available for statistical analyses. The Institutional Review Board of Texas Tech University, Lubbock, Texas, USA (IRB2020-288) approved the study on 25 March, 2020.

Data collection for the study was conducted after the US Food and Drug Administration (FDA) emergency authorized the Pfizer-BioNTech (11 December, 2020) and Moderna (13 December, 2020) vaccines [1]. At the time, fewer than 4.2 million vaccines had been administrated (2 January, 2021) [23]. Moreover, the country was experiencing what has been the largest number of daily cases and deaths: more than 2000 deaths and more than 187,000 new cases daily (largest numbers were reached around 9-13 January, 2021) [24].

\subsection{Questions}

The section with the CV questions began by providing respondents with an explanation of the vaccine to prevent COVID-19 (see Appendix 1). The vaccine description included information about its efficacy and price. Vaccine efficacy was described as the reduction in an individual's infection risk after vaccination relative to the infection risk of another individual who has not received the vaccine. When the survey was conducted, two approved vaccines against COVID-19 were already available in the USA with reported efficacies of about $95 \%$ [1]. Moreover, the FDA requires a minimum efficacy rate of 50\% for COVID-19 vaccine approval; thus, the $\mathrm{CV}$ questions considered three efficacy levels: 50, 70, and 95\% [25, 26].

Two initial screening questions were used to differentiate individuals' WTP for the vaccine and individuals willing to get vaccinated if a payment was offered: (1) Would you be willing to pay to get a coronavirus vaccine immediately? (2) Would you accept getting vaccinated immediately if the vaccine was free? (asked if individuals answered "No" or "I don't know" to the previous question) (Fig. 1). Individuals willing to pay for the vaccine were asked first whether they would buy a COVID-19 vaccine at an initial price assigned randomly. If they answered "Yes" to the initial price, they were asked whether they would buy the vaccine at a higher price. If the respondent answered "No" to the initial price, they were offered the vaccine at a lower price.

Individuals not willing to accept the vaccine for free were asked whether they would get the vaccine if offered an initial payment value assigned randomly. If they answered "Yes" to 


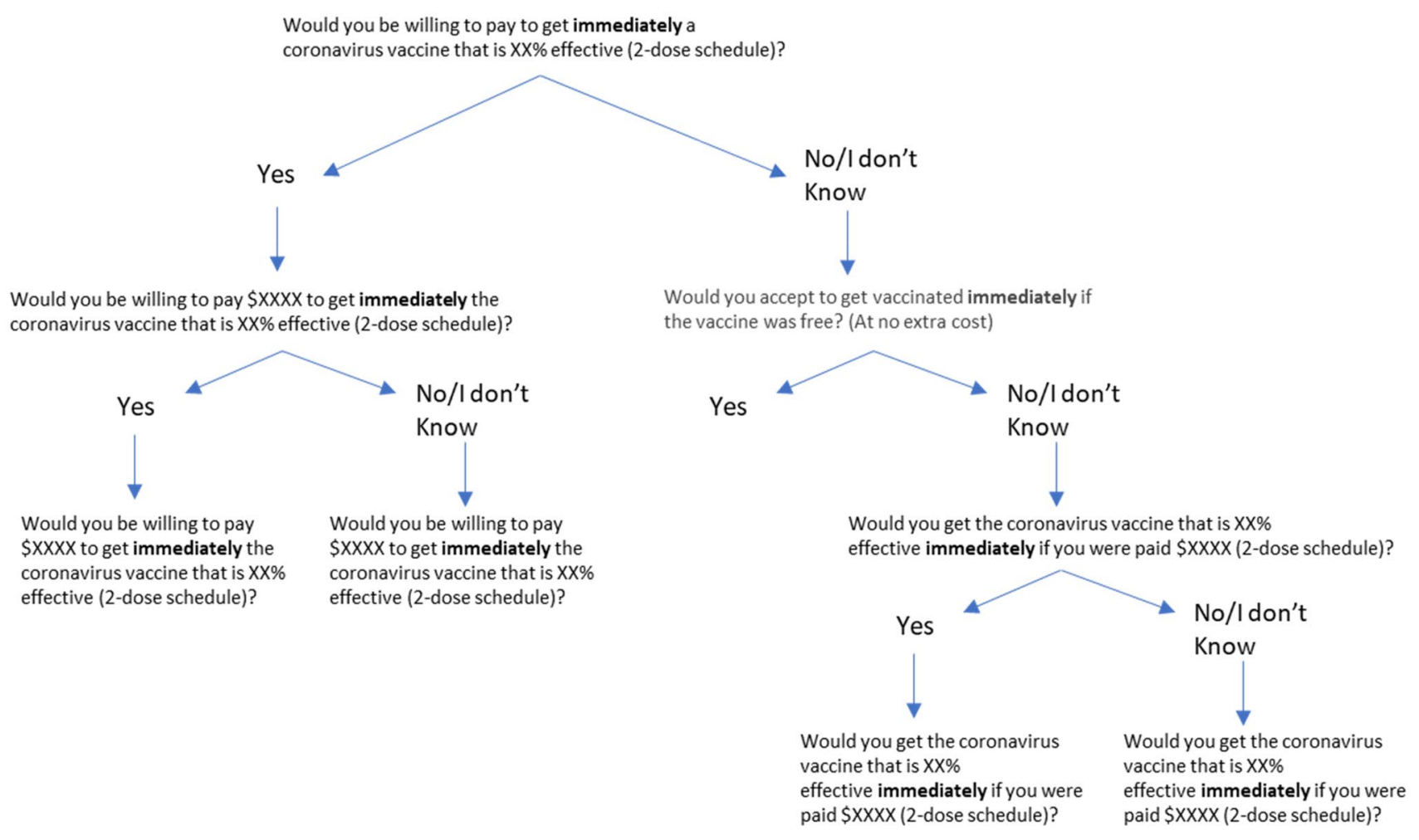

Fig. 1 Decision tree contingent valuation procedure

the initial offer, they were asked whether they would accept the vaccine at a lower payment value. If the respondent answered "No" the initial offer, they were offered a higher payment to get vaccinated.

Prices and payments used in the CV were selected using an experimental sequential design with three rounds of surveys ( $n=100$ in the first round, $n=900$ in the second, and $n=1000$ in the third round), which has been shown to improve the efficiency of WTP and WTA estimation [27]. Prices used in the first round were determined based on estimated COVID-19 vaccine wholesale prices (US $\$ 4-U S \$ 50 /$ dose), a mark-up for vaccine delivery (US\$20-US\$40), and the possibility that some consumers would be willing to pay above these levels to get the vaccine immediately (about US\$100); thus, initial prices included: US\$25, US\$50, US\$100, US\$150, and US\$250 [28, 29]. Payments offered in the first round of surveys were US\$50, US\$150, and US\$ 250 . The initial price bids were US\$50, US\$100, and US $\$ 150$. The follow-up prices were US $\$ 25$ for respondents who answered "No" to the US\$50 initial price and US $\$ 250$ for respondents who answered "Yes" to the US\$150 initial price. The initial payment offered was US $\$ 150$. The followup payments were US $\$ 50$ for individuals that accepted the first offer and US\$250 for those that declined it.

Results from the first round of surveys were used to estimate preliminary WTP function models assuming a normal distribution. Parameters from the distribution were then used to select values covering approximately 10th-20th and 80th-90th percentiles of the distribution $[15,16]$. The following payments (negative prices) and prices were used in the second round of surveys: US\$-300, US\$-200, US\$-100, US\$50, US\$100, US\$200, US\$400, US\$600, and US $\$ 800$. The values were assigned following the same procedure used in the first round of surveys. Similarly, results from the second round of surveys were used to estimate a normal WTP distribution function model and define new bid values to cover approximately 10th-20th and 80th-90th percentiles of the distribution in the third round $[15,16]$. This was necessary, as the estimated parameters changed after the second round. The following prices were used in the third and last round of surveys: US\$-650, US\$-350, US\$-50, US\$100, US\$350, US\$600, US\$850, and US\$1100.

\subsection{Statistical Analyses}

Data were analyzed using SAS and MATLAB [30, 31]. First, descriptive statistics of the variables on interest were calculated. Next, individuals were classified into four vaccine acceptability/demand groups: (1) individuals not willing to get vaccinated no matter the amount offered, (2) individuals willing to get vaccinated if offered a payment, (3) individuals willing to get vaccinated if the vaccine was provided at no 
extra cost, and (4) individuals willing to pay for the vaccine. Group proportions were then computed and compared across the three-vaccine efficacy levels and sociodemographic characteristics using Chi-squared tests. Finally, parametric and nonparametric procedures were used to estimate the distribution of WTP and WTA values.

The combined distribution of WTP and WTA can be characterized as a mixture combining two models, one corresponding to positive preferences (WTP $>0$ ) and another corresponding to negative preferences (WTA $>0$ ) [equivalent to negative WTP] with a spike at zero to allow for WTP $=0$. [32] Using $W$ to represent both WTP and WTA values, the distributions for positive and negative preferences can be signified by the canonical cumulative density functions $F^{+}(W)$ and $F^{-}(W)$, respectively. $F^{+}(W)$ is defined for values of $\mathrm{W}>0$ and $F^{-}(W)$ for values $W<0$. The distribution can be written as

$\operatorname{Pr}(W \leq w)=\theta_{1} F^{+}(W)++\theta_{2} F^{-}(W)+\left(1-\theta_{1}-\theta_{2}\right)$.

This distribution represents three groups of individuals: the fraction $\theta_{1}$ of individuals willing to pay a positive amount for the vaccine $(W>0)$, the fraction $\theta_{2}$ willing to get vaccinated if paid $(W<0)$, and the fraction $\left(1-\theta_{1}-\theta_{2}\right)$ willing to get the vaccine for free $(W=0)$.

The nonparametric procedure to estimate Eq. (1) used a three-step process: (1) estimation of parameters $\theta_{1}$ and $\theta_{2}$, (2) estimation of $F^{+}(W)$ and $F^{-}(W)$, and (3) estimation of the entire distribution combining information from steps 1 and 2 with parameters $\theta_{1}$ and $\theta_{2}$ assumed to be fixed coefficients [32]. Estimation of both $F^{+}(W)$ and $F^{-}(W)$ was carried out using Turnbull nonparametric procedures [33]. Parameters $\theta_{1}$ and $\theta_{2}$ were estimated using the answers to the following questions: (1) Would you be willing to pay to get a coronavirus vaccine immediately? (2) Would you accept getting vaccinated immediately if the vaccine was free? (asked if individuals answered "No" or "I don't know" to the previous question), and (3) What is the minimum amount you are willing to accept to get the coronavirus vaccine immediately? (asked to those responding "No" or "I don't know" to both WTA bids).

Options given to respond to question 3 included: (a) I would not get vaccinated no matter the amount offered, and (b) Amount (write the amount in US\$). Answers to question 1 allowed the estimation of $\theta_{1}$. Answers to question 2 allowed the estimation of both $\left(1-\theta_{1}-\theta_{2}\right)$, and thus $\theta_{2}$. Responses to question 3 were only used to determine the total number of individuals in the market for COVID-19 vaccines but not to estimate model parameters. In other words, responses to question 3 were used to identify individuals willing to accept the vaccine but a higher payment from those not willing to get the vaccine no matter the amount offered. The nonparametric procedure only identifies points in the cumulative density function (CDF) [at the bid values]. The estimated models cannot be used to calculate probabilities at arbitrary prices (including payments); however, they provide summary information about the WTA and WTP distribution without the need for distributional assumptions.

The nonparametric procedure only identifies points in the $\mathrm{CDF}$ (at the bid values) function. The estimated models cannot be used to calculate probabilities at arbitrary points in the distribution function; however, they provide summary information about the WTA and WTP distribution without relying on distributional assumptions.

The parametric estimation of Eq. (1) used a twostep approach: (1) estimation of parameters $\theta_{1}$ and $\theta_{2}$ as described previously and (2) joint estimation of the probability model in Eq. (1) using maximum likelihood estimation procedures. $F^{+}(W)$ and $F^{-}(W)$ were assumed to follow truncated normal distributions with zero as the lower bound and upper bound, respectively [34]. In contrast to the nonparametric model, the parametric models allowed the testing of the efficacy level's effect on two features of the $\operatorname{Pr}(W \leq w)$ distribution: its effect on the $\theta_{1}$ and $\theta_{2}$ coefficients (i.e., the probability that individuals are willing to pay for the vaccine and the probability of accepting the vaccine if paid a positive amount, respectively), and the effect on the mean of the $F^{+}(W)$ and $F^{-}(W)$ distributions. Moreover, the parametric models can be used to calculate probabilities at any vaccine price.

\section{Results}

\subsection{Participants and Aggregate Vaccine Demand and Acceptability}

Most survey respondents had a bachelor's degree or higher (80\%), were employed (88\%), and were between 18 and 34 years of age (54\%); thus, the sample was, on average, younger, more educated, and had higher rates of employment than adult individuals in the US population (Table 1) [35, 36]. The sample also had a larger proportion of male, Hispanic, and higher income individuals; and a lower proportion of Black respondents than the US population. However, the sample's proportions of low-income and rural respondents were similar to those in the population (Table 1).

Most of the individuals (60\%: 95\% confidence interval [CI] 0.58-0.62) indicated they were willing to pay a positive amount for the COVID-19 vaccine; $13.7 \%$ (95\% CI $0.12-0.15$ ) said they would only accept the vaccine if given for free; $14.1 \%$ (95\% CI 0.13-0.16) were willing to take the vaccine only if paid to do so; and $12.2 \%$ (95\% CI $0.11-0.14$ ) were not willing to accept the vaccine. Thus, an overall $87.8 \%$ of the sample indicated they were willing to get vaccinated. A global Chi-square test rejected the null 
Table 1 Characteristics of survey participants

\begin{tabular}{|c|c|c|}
\hline \multirow[t]{2}{*}{ Variables } & Participants $(n=1895)$ & $\begin{array}{l}\text { US popula- } \\
\text { tion }[35 \text {, } \\
36]\end{array}$ \\
\hline & $\%(n)$ & $\%$ \\
\hline \multicolumn{3}{|c|}{ Age of respondent $(n=1872)$, years } \\
\hline $18-34$ & $53.90(1009)$ & 23.21 \\
\hline $35-54$ & $35.10(657)$ & 25.14 \\
\hline 55 or more & $11.00(206)$ & 29.40 \\
\hline \multicolumn{3}{|l|}{ Education $(n=1881)$} \\
\hline High school graduate or less & $6.50(123)$ & 26.90 \\
\hline Some college & $13.06(247)$ & 20.00 \\
\hline College graduate or more & $79.91(1511)$ & 41.70 \\
\hline \multicolumn{3}{|l|}{ Employment status $(n=1894)$} \\
\hline Employed & $88.02(1667)$ & 60.20 \\
\hline Unemployed & $4.96(94)$ & 2.90 \\
\hline Other & $7.02(133)$ & 36.40 \\
\hline \multicolumn{3}{|l|}{ Sex of respondents $(n=1868)$} \\
\hline Male & $58.24(1088)$ & 49.20 \\
\hline Female & $41.76(780)$ & 50.80 \\
\hline \multicolumn{3}{|c|}{ Hispanic or Latino background $(n=1855)$} \\
\hline Hispanic or Latino & $30.03(557)$ & 18.40 \\
\hline Non-Hispanic or Latino & $69.97(1298)$ & 81.60 \\
\hline \multicolumn{3}{|l|}{ Race of respondents $(n=1892)$} \\
\hline White & $67.49(1277)$ & 72.00 \\
\hline Black & $4.60(87)$ & 12.80 \\
\hline Other race & $27.91(528)$ & 15.20 \\
\hline \multicolumn{3}{|c|}{ Location of the household $(n=1868)$} \\
\hline Urban & $80.35(1501)$ & 82.46 \\
\hline Rural & $19.65(367)$ & 17.54 \\
\hline \multicolumn{3}{|c|}{ Average household income $(n=1894)$} \\
\hline Less than US $\$ 25,000$ & $18.06(342)$ & 18.10 \\
\hline US $\$ 25,000-U S \$ 49,000$ & $27.03(512)$ & 20.30 \\
\hline US\$50,000-US\$74,999 & $23.13(438)$ & 17.40 \\
\hline US\$75,000-US\$149,999 & $27.72(525)$ & 28.50 \\
\hline US $\$ 150,000$ or more & $4.07(77)$ & 15.70 \\
\hline
\end{tabular}

hypothesis that the proportion of individuals in each group was not associated with the efficacy level $\left(\chi^{2}(6)=22.173\right.$; $p=0.001$ ) (Table 2). Chi-square tests of proportions for separate demand groups also rejected the null hypotheses of no relationship between vaccine efficacy and the proportion of individuals willing to pay for the vaccine $(p<0.05)$, the proportion willing to accept it for free $(p<0.05)$, and the proportion not willing to get vaccinated but only at the $10 \%$ level ( $p=0.08$ ) (Table 2). The test failed to reject the null hypothesis of no association between vaccine efficacy level and the proportion willing to accept the vaccine if paid ( $p=$ 0.38). The proportion of individuals not willing to accept the vaccine decreased as the efficacy level increased, going from $14.5 \%$ for the vaccine with a $50 \%$ efficacy level to 11.7 and $10.3 \%$ for vaccines with 70 and $95 \%$ efficacy levels, respectively. In contrast, the proportion of individuals willing to pay for the vaccine increased with the efficacy levels. At the $50 \%$ efficacy level, the proportion of individuals willing to pay for the vaccine was $53.5 \%$. This proportion increased to $62 \%$ of individuals in the $70 \%$ vaccine efficacy group, and $65 \%$ in the $95 \%$ vaccine efficacy group (Table 2 ).

Individuals not willing to get vaccinated $(12.2 \%$ of the sample) included individuals answering no to the sequence of WTP and WTA questions (see Fig. 1), and who also selected "I would not get vaccinated no matter the amount offered" as the answer to a follow-up question inquiring about their minimum WTA value to get vaccinated. Reasons for rejecting the vaccines included "I don't trust the vaccines" (42.86\%), 'I don't think a vaccine is necessary"(22.08\%), "Already had COVID" (4.33\%), and "Other reasons" (45.89\%). 
Table 2 Number and percentage of individuals willing to get vaccinated classified by their willingness to pay and willingness to accept values ( $n$ $=1895)$

\begin{tabular}{|c|c|c|c|c|c|c|}
\hline & Total $(n=1895)$ & $\begin{array}{l}\text { Willing to pay for } \\
\text { COVID-19 vaccine }\end{array}$ & $\begin{array}{l}\text { Willing to accept } \\
\text { COVID-19 vaccine for } \\
\text { free }\end{array}$ & $\begin{array}{l}\text { Willing to accept } \\
\text { COVID-19 vaccine if } \\
\text { get paid }\end{array}$ & $\begin{array}{l}\text { Not willing to accept } \\
\text { COVID-19 vaccine }\end{array}$ & $p$ value $^{\mathrm{a}}$ \\
\hline & $\%(n)$ & $\%(n)$ & $\%(n)$ & $\%(n)$ & $\%(n)$ & \\
\hline Efficacy & & & & & & 0.0011 \\
\hline $50 \%$ & $32.88(623)$ & $53.45(333)$ & $16.69(104)$ & $15.41(96)$ & $14.45(90)$ & \\
\hline $70 \%$ & $35.99(682)$ & $61.79(421)$ & $13.78(94)$ & $12.76(87)$ & $11.73(80)$ & \\
\hline $95 \%$ & $31.13(590)$ & $64.92(383)$ & $10.34(61)$ & $14.41(85)$ & $10.34(61)$ & \\
\hline Combined & $100.00(1895)$ & 60.00 (1137) & $13.67(259)$ & $14.14(268)$ & $12.19(231)$ & \\
\hline$p$ value $\mathrm{e}^{\mathrm{b}}$ & & 0.0001 & 0.0056 & 0.3798 & 0.0827 & \\
\hline
\end{tabular}

${ }^{\mathrm{a}} \chi^{2}$ global test of proportions for all groups

${ }^{\mathrm{b}} \chi^{2}$ test of proportions within each demand group

Chi-square tests rejected the null hypotheses that the proportion of individuals in each vaccine demand group was not associated with the sociodemographic characteristics (all $p$ values $\leq 0.05$ ) (Table 3). The groups willing to pay for the vaccine or accept it for free had a higher proportion of younger individuals, higher levels of education, and employment (all $p$ values $\leq 0.001$ ) than those willing to get vaccinated if paid or not willing to get vaccinated. The group willing to pay for the vaccine or to get it for free had a higher proportion of Hispanic or Latino individuals, a lower proportion of Black individuals, a lower proportion of female individuals, and a higher proportion living in urban areas when compared with individuals willing to accept the vaccine of if paid or not willing to get the vaccine. Finally, relative to other groups, the group willing to pay for the vaccine had a larger proportion of high-income individuals and a lower proportion of low-income individuals.

\subsection{WTA and WTP Distribution Function}

The estimated nonparametric Turnbull WTA and WTP cumulative distribution functions for each level of efficacy (CDFs) are presented in Table 4. Two distribution functions are presented for each efficacy level. The left side of Table 4 includes the estimated CDF values considering only individuals willing to accept a vaccine (if paid, for free, or willing to pay for it) [conditional CDF]. The right side of Table 4 adjusts the CDF values on the left to represent the proportion of individuals in the entire population, including those not willing to get vaccinated (unconditional CDF). The CDF values are interpreted in relation to the upper tier of the bid ranges. For example, the adjusted $\mathrm{CDF}$ value for the vaccine with $50 \%$ efficacy indicates that $6.2 \%$ of respondents were willing to get vaccinated if paid US $\$ 650$ or more, $15.4 \%$ were willing to get vaccinated if paid a positive amount, $32.1 \%$ were willing to get vaccinated for free or if paid a positive amount, and $43.7 \%$ were willing to get vaccinated if the price was US\$350 or less. Moreover, $20.1 \%$ $((0.856-0.655) \times 100 \%)$ of respondents were willing to pay US\$1100 or more for the vaccine with a $50 \%$ efficacy level.

The estimated percentage of individuals willing to get vaccinated if paid US\$650 (the highest payment offered) was very similar (about 6\%) across the three efficacy levels. However, the estimated proportion of individuals willing to pay US $\$ 1100$ (the highest price considered) increased as the level of efficacy increased, going from $20.1 \%$ for the vaccine with a $50 \%$ efficacy level to 22.5 and $27.2 \%$ for vaccines with 70 and $95 \%$ efficacy levels, respectively. The median WTP values (left side of Table 3) were estimated in the US\$250-US\$350 range for the $50 \%$ efficacy vaccine and US $\$ 350-U S \$ 400$ for vaccines with 70 and $95 \%$ levels of efficacy.

Table 5 shows the estimated values for the parametric model for $\operatorname{Pr}(W \leq w)$. The null hypothesis that the efficacy level does not affect the values of the $\theta_{1}$ and $\theta_{2}$ coefficients was rejected in favor of the alternative hypothesis that the coefficients are affected by the efficacy level $\left(\chi^{2}(4)=16.93\right.$; $p=0.002)$. In contrast, the null hypothesis that the efficacy level affects the means of the $F^{+}(W)$ and $F^{+}(W)$ distribution functions was not rejected $\left(\chi^{2}(4)=2.59 ; p=0.629\right)$. Both conditional WTP and WTA distributions were asymmetric and had long tails, as the absolute mean values were larger than the absolute values of the medians. Among the group willing to get vaccinated if paid, the mean WTA value was US\$716.17, whereas the median was US\$525. The mean WTP among those willing to pay for the vaccine was US $\$ 1147.06$ with a median value of US $\$ 813.71$. The overall mean WTP across all individuals willing to get vaccinated was US\$705.81. 
Table 3 Characteristics of survey participants by vaccine demand group

\begin{tabular}{|c|c|c|c|c|c|c|}
\hline & Total sample & $\begin{array}{l}\text { Willing to pay } \\
\text { for COVID-19 } \\
\text { vaccine }\end{array}$ & $\begin{array}{l}\text { Willing to accept } \\
\text { COVID-19 vaccine } \\
\text { for free }\end{array}$ & $\begin{array}{l}\text { Willing to accept } \\
\text { COVID-19 vaccine } \\
\text { if paid }\end{array}$ & $\begin{array}{l}\text { Not willing to } \\
\text { accept COVID-19 } \\
\text { vaccine }\end{array}$ & $p$ value $^{\mathrm{a}}$ \\
\hline Variables & $\%(n)$ & $\%(n)$ & $\%(n)$ & $\%(n)$ & $\%(n)$ & \\
\hline \multicolumn{6}{|c|}{ Age of respondent ( $n=1872$ ), years } & $<0.0001$ \\
\hline $18-34$ & $53.90(1009)$ & $60.46(679)$ & $51.17(131)$ & $39.77(105)$ & $41.05(94)$ & \\
\hline $35-54$ & $35.10(657)$ & $29.65(333)$ & $39.06(100)$ & $45.45(120)$ & $45.41(104)$ & \\
\hline 55 or more & $11.00(206)$ & $9.88(111)$ & $9.77(25)$ & $14.77(39)$ & $13.54(31)$ & \\
\hline \multicolumn{6}{|l|}{ Education $(n=1881)$} & $<0.0001$ \\
\hline $\begin{array}{l}\text { High school graduate } \\
\text { or less }\end{array}$ & $6.54(123)$ & $3.63(41)$ & $10.89(28)$ & $11.32(30)$ & $10.48(24)$ & \\
\hline Some college & $13.13(247)$ & $8.32(94)$ & $12.45(32)$ & $24.91(66)$ & $24.02(55)$ & \\
\hline $\begin{array}{l}\text { College graduate or } \\
\text { more }\end{array}$ & $80.33(1511)$ & 88.05 (995) & $76.65(197)$ & $63.77(169)$ & $65.50(150)$ & \\
\hline \multicolumn{6}{|c|}{ Employment status $(n=1894)$} & $<0.0001$ \\
\hline Employed & $88.01(1667)$ & $93.40(1061)$ & $81.47(211)$ & $78.36(210)$ & $80.09(185)$ & \\
\hline Unemployed & $4.96(94)$ & $2.11(24)$ & $7.34(19)$ & $10.45(28)$ & $9.96(23)$ & \\
\hline Other & $7.02(133)$ & $4.49(51)$ & $11.20(29)$ & $11.19(30)$ & $9.96(23)$ & \\
\hline \multicolumn{6}{|c|}{ Sex of respondents $(n=1868)$} & $<0.0001$ \\
\hline Male & $58.24(1088)$ & $63.49(713)$ & $58.04(148)$ & $50.38(132)$ & $41.67(95)$ & \\
\hline Female & $41.76(780)$ & $36.51(410)$ & $41.96(107)$ & $49.62(130)$ & $58.33(133)$ & \\
\hline \multicolumn{6}{|c|}{ Hispanic or Latino background $(n=1855)$} & $<0.0001$ \\
\hline Hispanic or Latino & $30.03(557)$ & $42.64(475)$ & $19.37(49)$ & $5.77(15)$ & $7.89(18)$ & \\
\hline Non-Hispanic or Latino & $69.97(1298)$ & $57.36(639)$ & $80.63(204)$ & $94.23(245)$ & $92.11(210)$ & \\
\hline \multicolumn{6}{|c|}{ Race of respondents $(n=1892)$} & $<0.0001$ \\
\hline White & $67.49(1277)$ & $64.37(730)$ & $69.88(181)$ & $77.61(208)$ & $68.40(158)$ & \\
\hline Black & $4.60(87)$ & $3.88(44)$ & $1.54(4)$ & 7.09 (19) & $8.66(20)$ & \\
\hline Other race & $27.91(528)$ & $31.75(360)$ & $28.57(74)$ & $15.30(41)$ & $22.94(53)$ & \\
\hline \multicolumn{6}{|c|}{ Location of the household $(n=1868)$} & $<0.0001$ \\
\hline Urban & $80.35(1501)$ & $84.35(943)$ & $79.69(204)$ & $70.19(186)$ & $73.36(168)$ & \\
\hline Rural & $19.65(367)$ & $15.65(175)$ & $20.31(52)$ & $29.81(79)$ & $26.64(61)$ & \\
\hline \multicolumn{6}{|c|}{ Average household income $(n=1894)$} & 0.005 \\
\hline Less than US $\$ 25,000$ & $18.06(342)$ & $15.74(179)$ & $25.19(65)$ & $19.40(52)$ & $19.91(46)$ & \\
\hline US $\$ 25,000-U S \$ 49,000$ & $27.03(512)$ & $25.59(291)$ & $27.52(71)$ & $33.21(89)$ & $26.41(61)$ & \\
\hline US $\$ 50,000-U S \$ 74,999$ & $23.13(438)$ & $24.71(281)$ & $20.16(52)$ & $20.52(55)$ & $21.65(50)$ & \\
\hline US $\$ 75,000-U S \$ 149,999$ & $27.72(525)$ & $30.26(344)$ & $22.09(57)$ & $22.76(61)$ & $27.27(63)$ & \\
\hline US $\$ 150,000$ or more & $4.07(77)$ & $3.69(42)$ & $5.04(13)$ & $4.10(11)$ & $4.76(11)$ & \\
\hline
\end{tabular}

${ }^{\mathrm{a}} \chi^{2}$ test of proportions.

\section{Discussion}

Knowledge about individuals' acceptance and demand for a vaccine against severe acute respiratory syndrome coronavirus 2 is essential for designing and implementing vaccination campaigns. Whereas several studies have evaluated the acceptability of a COVID-19 vaccine in the USA [37, 38], this study evaluates the demand using the economic concepts of WTP and WTA.

This study shows that about $86-90 \%$ of the US population would be willing to get vaccinated. This percentage includes about $13-15 \%$ willing to get vaccinated if paid a positive amount. Therefore, it is estimated that about $68-75 \%$ of individuals would get vaccinated if the vaccine were free, which is the current situation in the country $(68,72$, and $75 \%$ for 50,70 , and $95 \%$ vaccine efficacy levels, respectively). These estimates are in line with the estimated value obtained by the Kaiser Family Foundation (KFF) Health Tracking Poll conducted between 30 November and 8 December, 2020, which uses a different approach to measure vaccine acceptability [37]. The KFF asked individuals about the likelihood of getting vaccinated "if a coronavirus vaccine was determined to be safe by scientists and was available for free to everyone who wanted it." In the KFF survey, 71\% 
Table 4 Nonparametric willingness to accept and pay distribution functions $(n=$ 1895)

\begin{tabular}{|c|c|c|c|c|c|c|}
\hline \multirow[t]{3}{*}{ Efficacy (\%) } & \multicolumn{6}{|c|}{ Turnbull CDF } \\
\hline & \multicolumn{3}{|c|}{ Conditional CDF $(n=1664)$} & \multicolumn{3}{|c|}{ Unconditional CDF $(n=1895)$} \\
\hline & 50 & 70 & 95 & 50 & 70 & 95 \\
\hline \multicolumn{7}{|l|}{ Bid range (US\$) } \\
\hline$<-650$ & 0.073 & 0.072 & 0.073 & 0.062 & 0.064 & 0.065 \\
\hline-650 to -350 & 0.124 & 0.092 & 0.097 & 0.106 & 0.081 & 0.087 \\
\hline-350 to -300 & 0.135 & 0.092 & 0.097 & 0.116 & 0.081 & 0.087 \\
\hline-300 to -250 & 0.139 & 0.103 & 0.097 & 0.119 & 0.091 & 0.087 \\
\hline-250 to -200 & 0.143 & 0.103 & 0.102 & 0.122 & 0.091 & 0.091 \\
\hline-200 to -150 & 0.149 & 0.112 & 0.127 & 0.128 & 0.099 & 0.114 \\
\hline-150 to -100 & 0.155 & 0.121 & 0.127 & 0.133 & 0.107 & 0.114 \\
\hline-100 to -50 & 0.164 & 0.128 & 0.144 & 0.140 & 0.113 & 0.129 \\
\hline-50 to 0 & 0.180 & 0.145 & 0.161 & 0.154 & 0.128 & 0.144 \\
\hline 0 & 0.375 & 0.310 & 0.276 & 0.321 & 0.274 & 0.248 \\
\hline $0-25$ & 0.405 & 0.336 & 0.320 & 0.347 & 0.297 & 0.287 \\
\hline $25-50$ & 0.436 & 0.336 & 0.346 & 0.373 & 0.297 & 0.310 \\
\hline $50-100$ & 0.436 & 0.386 & 0.396 & 0.373 & 0.341 & 0.355 \\
\hline $100-150$ & 0.452 & 0.444 & 0.458 & 0.387 & 0.392 & 0.411 \\
\hline $150-200$ & 0.467 & 0.455 & 0.468 & 0.400 & 0.402 & 0.420 \\
\hline $200-250$ & 0.489 & 0.488 & 0.484 & 0.419 & 0.431 & 0.434 \\
\hline $250-350$ & 0.510 & 0.491 & 0.484 & 0.437 & 0.434 & 0.434 \\
\hline $350-400$ & 0.552 & 0.538 & 0.517 & 0.473 & 0.475 & 0.464 \\
\hline $400-600$ & 0.591 & 0.589 & 0.579 & 0.506 & 0.520 & 0.519 \\
\hline $600-800$ & 0.610 & 0.628 & 0.659 & 0.522 & 0.555 & 0.591 \\
\hline $800-850$ & 0.632 & 0.664 & 0.659 & 0.541 & 0.586 & 0.591 \\
\hline $850-1100$ & 0.765 & 0.745 & 0.698 & 0.655 & 0.658 & 0.626 \\
\hline$>1100$ & 1.000 & 1.000 & 1.000 & 0.856 & 0.883 & 0.897 \\
\hline
\end{tabular}

Note: estimated probability values in the conditional CDF correspond to individuals willing to get vaccinated. Estimated probability values in the unconditional CDF are for all individuals in the population

$C D F$ cumulative density function of individuals indicated they would get the vaccine (41\% "would definitely" get the vaccine, and 30\% "would probably" get it). The KFF survey also included the "probably not get it" (12\%) and "definitely not get it" (15\%) options for respondents. These values are similar to the proportion willing to take the vaccine if paid (14\%) and to the proportion of individuals not willing to get the vaccine even if paid (about 13\%). It is important to note that KFF sample seems to be closer to the US population across several characteristics, including the proportion of male individuals (49\%), employed (56\%), and Hispanic respondents (16\%); and thus differs from our sample, which had a higher proportion of individuals in these groups. However, the KFF sample did not perfectly match all the characteristics of the US population as it included, for example, larger proportions of individuals with high school education and some college: 38 , $30 \%$ respectively, compared to 27 and $20 \%$ in the population; and consequently, a lower proportion of individuals with at least a bachelor's degree (31\% compared to $42 \%$ in the US population) (Table 1).
Aggregate vaccine acceptability results differ from another study conducted during the same period (25 November to 8 December, 2020) [38], which reports significantly lower vaccine acceptability estimates (56\%); however, the study did not include price as part of the acceptability question (i.e., the question asked was "How likely are you to get vaccinated for coronavirus once a vaccine is available to the public?"). A review paper assessing the impact of survey design on COVID-19 vaccination intention responses found that studies framing the intention question in more positive terms tend to result in higher positive responses [39]. The COVID-19 vaccine described to respondents in this study (see Appendix 1) indicated the vaccine was "FDA authorized" and "for use in the US," and thus similar to the statement included in the KFF question that a "vaccine was determined to be safe by scientists". Hence, this study's approach to measuring vaccine acceptability (based on a contingent valuation approach with "Yes" or "No" types of questions) seems to yield comparable overall estimates of vaccine acceptability when compared to some surveys 
Table 5 Parametric WTP and WTA distribution function (only includes individuals willing to get vaccinated) $[n=1664]$

\begin{tabular}{lll}
\hline Features of the WTA and WTP distribution & Vaccine efficacy $(\%)$ & 70 \\
\cline { 2 - 2 } & 95 & $0.699(0.019)$ \\
\hline$\theta_{1}, \theta_{2}$, and $\left(1-\theta_{1}-\theta_{2}\right)$ & & $0.145(0.014)$ \\
$\theta_{1}$ (proportion WTP for vaccine) & $0.720(0.020)$ & $0.156(0.015)$ \\
$\theta_{2}$ (proportion willing to get vaccinated if paid) & $0.161(0.017)$ & $0.625(0.020)$ \\
$\left(1-\theta_{1}-\theta_{2}\right)$ (proportion willing to get vaccinated for free) & $0.115(0.014)$ & $0.180(0.017)$ \\
WTA distribution & & $0.195(0.017)$ \\
Intercept & $-485.87(59.40)$ & \\
Standard deviation & $76.72(5.84)$ & \\
Mean & $-716.17(60.97)$ & $-525.91(50.44)$ \\
Median & & \\
WTP distribution & $55.00(23.67)$ & \\
Intercept & $22.13(3.13)$ & \\
Standard deviation & $1147.06(50.34)$ & \\
Mean & $813.71(38.87)$ & \\
Median & $722.78(53.12)$ & \\
WTA and WTP distribution $\operatorname{Pr}(W \leq w)$ & & \\
Mean & & \\
\hline
\end{tabular}

Note: all standard errors (in parenthesis) calculated using 1000 bootstrapping samples. The intercept and standard deviations of the WTA and WTP distributions correspond to the mean and standard deviation of the underlying uncensored normal distributions. Mean and medians correspond to the censored normal distributions

WTA willingness to accept, WTP willingness to pay

conducted at about the same period using questions about the likelihood of getting vaccinated and framed similarly in terms of stating quality assurances and price levels.

In contrast to the approach of evaluating vaccine acceptability based on the likelihood of getting vaccinated, the proposed method based on WTP and WTA allows for assessing vaccine demand at other "price levels," including the demand for the vaccine if individuals were offered financial compensation. According to our estimated demand model, a payment of about US $\$ 100$, the amount being offered by some companies, would only increase vaccine demand by about $2 \%$ of the population (see Fig. 2) [6]. With a payment of about US\$500, an additional $6.0-7.5 \%$ of the population would accept getting vaccinated. From a different perspective, payments of US\$500 are needed to encourage vaccination in approximately $48 \%$ of individuals willing to get vaccinated if paid. This proportion increases to about $74 \%$ with payments of about US $\$ 1000$. Therefore, payments between US\$500 and US\$1000 would allow reaching vaccination rates of $78-82 \%$ and $82-86 \%$ of the population, respectively, where the upper limits of the range correspond to the vaccine with a 95\% efficacy level and the lower to a vaccine with a $50 \%$ efficacy level.

Contrary to this study's findings that financial incentives can increase vaccine uptake, an experiment conducted in Germany found that payments did not affect COVID-19 vaccination intentions; however, the maximum amount of incentives offered to project participants was only EUR 200 [22]. However, a study conducted in the USA using financial incentives between US $\$ 1000$ and US $\$ 2000$ also found their use increased vaccine uptakes by about $8 \%$ relative to the non-incentive baseline. The payment amount was not found to be relevant [20].

In addition to the effects on vaccine uptake, providing financial incentives to promote vaccination also has equity and access implications. For example, as argued by Jecker, the use of payments could potentially exert more force and coercion on individuals of lower sociodemographic groups [40]. The counterargument is that because disadvantaged individuals have been more affected by the pandemic, it is beneficial to use mechanisms that increase vaccination rates among these groups. Financial incentives can also help increase access to vaccines as getting vaccinated may include additional costs (e.g., transportation, the opportunity cost of wages), which can be covered with the payments. It is important to mention the ongoing debate regarding ethical and behavioral aspects of providing financial incentives for vaccines $[2,40]$. For instance, some scientists have argued that financial incentives may discourage some individuals from getting vaccinated as payments can be perceived as an indication that the vaccine is risky [2].

There are also multiple open questions regarding the implementation of a payment mechanism. For example, who should provide the incentives, the government or employers? 
Fig. 2 Aggregate demand curves for the COVID-19 vaccine. USD US Dollars

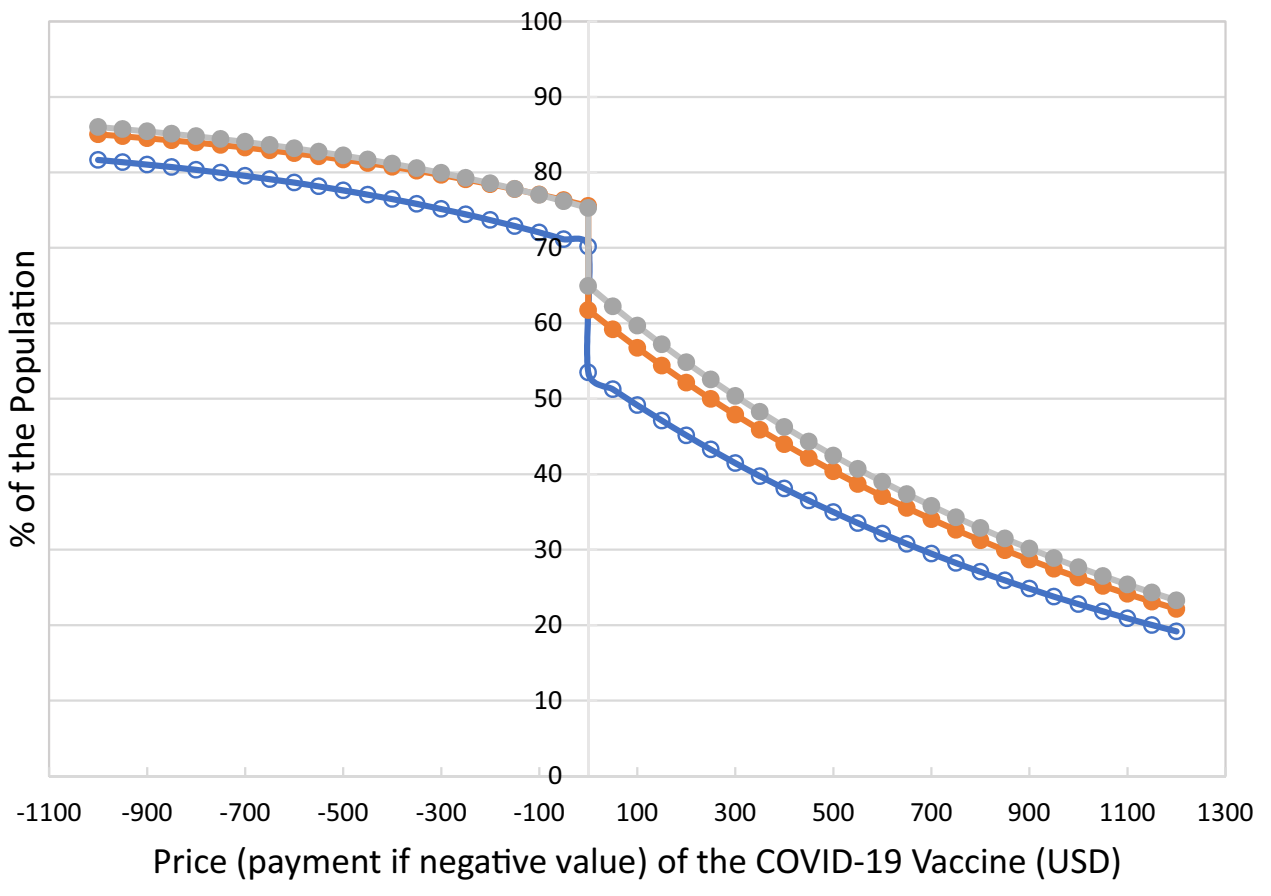

$-50 \%$ efficacy $-70 \%$ efficacy $-25 \%$ efficacy
And when? In the USA, the government provided three rounds of cash payments of up to $\$ 1400$ to adult taxpayers during the pandemic. These payments could have been made conditional (or could be made) on getting vaccinated. The impact and reach of government payment programs would also be more significant than individual employer efforts. However, mechanisms to provide financial help to those in need but who refused to get vaccinated would need to be considered. From a different perspective, vaccination payment programs implemented by employers may be perceived with less suspicion by those individuals that mistrust the government [41]. In terms of the timing of the payments, if payments are not offered to those already vaccinated, this could create perceptions of unfairness and increase delays in accepting new vaccines in the future.

The estimated mean and median WTP values for the vaccine provide insights into the private economic benefits of COVID-19 vaccines. The results reflect large mean WTP values (among individuals willing to get vaccinated): US\$594, US\$706, and US\$723 for vaccines with efficacy levels of 50, 70, and 95\%, respectively. Even though the US population willing to get vaccinated includes a significant proportion of individuals willing to do so only if the vaccine is free or compensated for $(25-30 \%)$, there is also a high proportion (20-27\%) willing to pay US\$1100 or more for the vaccine, which increases the average WTP value (Table 3 ).

Several studies have evaluated WTP for a COVID19 vaccine around the world, including Chile (US\$184.72-US\$232), Ecuador (US\$147), Romania
(US\$23.8-238; using an exchange rate of EUR 1-1.19 on 20 August, 2020), Indonesia (US\$57.20), Malaysia (US\$30.66), and Kenya (at least US\$49.81) [12-17, 42]. The potential source of differences includes the country's economic conditions, with people in higher income countries having higher average WTP values for the vaccine. Dissimilarities in mean WTP values may also reflect differences in the methods used and the status of COVID-19 in each country at the time data were collected.

The study's results also found evidence that COVID19 vaccine efficacy affected individuals' demand for the vaccine, including both the overall willingness to get vaccinated and the WTP for the vaccine. Several previous studies have found that COVID-19 vaccine attributes affect the demand for the vaccine [26, 42-47]. A substantial and significant effect of vaccine efficacy was found in Australia, where consumers were found to be willing to pay US\$23.92 for a $1 \%$ increase in vaccine efficacy; this implies a US\$360 increase in WTP when comparing, for example, COVID-19 vaccines with $84 \%$ and $99 \%$ efficacy levels (minimum and maximum levels used in that study). Moreover, some literature indicates that vaccine uptake can be increased if people are provided the freedom to choose the vaccine they believe is best (e.g., vaccines with higher efficacy levels) [48].

The level of COVID-19 vaccine efficacy is one of the attributes that has received more attention in the media. The reported efficacy levels of the first two vaccines approved in the USA (Pfizer and Moderna) were about 95\%, which may 
have changed individuals' expectations about what a "good" vaccine is expected to be $[16,17,49]$. Communication about vaccine quality should encompass the ability of a vaccine to prevent a disease and the reduction of other negative health outcomes (e.g., hospitalization and death) associated with the disease if infected.

Consistent with previous studies, vaccine demand and acceptability were found to differ across subgroups of the population. Whereas Black individuals only account for about $4.6 \%$ of the total sample, their proportions in the groups who were not willing to get the vaccine or accept it only if paid were significantly larger ( 8.7 and $7.1 \%$, respectively). Higher levels of vaccine hesitancy among Black individuals are well documented in the literature and explained by various factors, including lower access to and mistrust of healthcare services and medicine and lower levels of awareness and education $[50,51]$. In line with prior studies, vaccine acceptability was lower among individuals located in rural areas and individuals with lower levels of education, which have also been attributed to more insufficient access to and trust in healthcare services and medicine [39, 50]. A common factor used to explain low vaccine acceptability levels among Black, rural, and low education groups is the concern about vaccine costs. As this study considers vaccine price (including financial incentives), our findings suggest no price-related issues are more important for a significant proportion of the population.

The group of individuals not willing to accept the vaccine and the group willing to accept the vaccine only if paid was found to include a larger proportion of female individuals (58, and $49 \%$, respectively), in comparison to the proportion of female individuals in the groups willing to pay for the vaccine $(37 \%)$ or willing to get vaccinated for free $(42 \%)$. Lower vaccine acceptance among women relative to men has been constantly found in multiple previous studies [39, 51]. Female individuals are reported to be more likely to avoid risky behaviors, more likely to practice preventive measures to prevent COVID-19, and more concerned about vaccine safety and efficacy, which in turn might help explain their lower levels of vaccine demand and acceptability $[39,50$, 51].

Another demographic characteristic found to be associated with vaccine demand is an individual's ethnicity. Overall, our findings show that most Hispanic/Latino individuals are willing to accept the vaccine. The proportion of Hispanic individuals in the sample is about $30 \%$, but no more than $8 \%$ in the groups of individuals willing to accept the vaccine only if paid or not willing to accept it. Previous studies report mixed findings concerning COVID-19 vaccine acceptability among Hispanic individuals, but most report higher vaccine acceptability [39].

Overall, the evaluation of factors associated with COVID19 vaccine acceptability and demand provides results consistent with previous literature, although the procedure used to assess vaccine acceptability is based upon an individual's WTP and WTA for the vaccine. In contrast, most previous studies assess vaccine acceptability directly.

This study has several limitations. First, data were collected online; thus, it was only available to individuals with access to the Internet, computers, and mobile phones. Second, various sample characteristics differ from those in the population. Despite these two limitations, the overall estimates of vaccine acceptability in this study are in line with previous studies; however, the estimated WTA and WTP distribution might not be representative of the population. Third, individuals' perceptions about products, including vaccines, change through time as more information becomes available (e.g., vaccine safety information) and/or there are changes in the context (e.g., rates of infection in the population); thus, WTP and WTA values are also likely to change. Fourth, there is some research indicating that people have difficulty understanding the concept of vaccine efficacy, which might have affected the results [52]. Finally, we only consider payments as a financial incentive and vaccine efficacy as a quality attribute. Future work should consider using other vaccine quality dimensions beyond its ability to prevent the disease (e.g., length of protection, safety) and other financial incentives such as lotteries. Future research should also consider evaluating the effect of sociodemographic characteristics, risk perceptions, and other vaccine characteristics on WTP and WTA values.

A challenge with using contingent valuation methods to evaluate the demand for a vaccine is the need to obtain information about the entire WTP and WTP probability distribution, including the distribution's tails. Characterization of the tails requires using a higher number of bid values and larger samples relative to studies that focus only on acceptability utilizing the concept of the likelihood of getting vaccinated.

\section{Conclusions}

Overall, the COVID-19 vaccine is highly valued by US individuals, and about $88 \%$ of its population would accept vaccination; however, about $14 \%$ indicate they would get vaccinated only if compensated. We also find that the level of financial incentives currently offered (about US\$100) by companies to their employees to get vaccinated would increase vaccination rates by about $2 \%$. It is estimated that financial incentives of about US\$500 or more would be needed to get $50 \%$ or more of this group vaccinated.

Finally, we found that vaccine efficacy level affects both the overall demand for the vaccine and the WTP for it. 
Larger differences in both acceptability and WTP were observed when comparing vaccines with 50 and $70 \%$ efficacy levels relative to the difference between vaccines with 70 and $95 \%$ efficacy levels.

\section{Appendix 1: Description paragraph for contingent valuation}

There is now one FDA authorized Covid-19 vaccine for use in the US, and two more expected to be approved soon; however, the vaccine will not yet be available for everyone in the population. We would like to know what you would do if you had access to the vaccine at a convenient location like a health or medical center.

Your honest answers to the question below are important to better understand the potential demand for the vaccine. The results will be disseminated to government, non-government organizations, and the public.

The vaccine requires a 2 -dose schedule and is $70 \%$ effective. In other words, of 100 people receiving the vaccine, there will be 70 of the people who have taken the vaccine that are protected. The other people who have been vaccinated will not be protected against coronavirus disease, even though they have taken the vaccine.

Would you be willing to pay to get immediately a coronavirus vaccine that is 70\% effective (2-dose schedule)? (see Fig. 1 for subsequent sequence of questions).

\section{Declarations}

Funding Texas Tech University provided funding for the preparation of this article.

Conflict of interest Carlos E. Carpio, Ioana A. Coman, Oscar Sarasty, and Manuel Garcia declare that they have no conflict of interest.

Ethics approval The project associated with this article was presented to the ethics committee of the institution. This research has exemption status: anonymous and non-sensitive survey research (IRB2020-288 approved the study on 25 March, 2020).

Consent to participate Informed consent was obtained from all the respondents included in the study.

Consent for publication Not applicable.

Availability of data and material The datasets that support the findings of this study are available from the corresponding author upon reasonable request.

Code availability The code that supports the findings of this study is available from the corresponding author upon reasonable request.

Author contributions Contributed to the conceptualization of the study, methodology: CC, IC, OS, MG. Formal analysis: CC, OS. Resources, writing, and original draft preparation: CC. Contributed to formal analysis, investigation, writing, reviewing, and editing the final article: CC, IC, OS, MG. All authors read and approved the final manuscript.

\section{References}

1. The New York Times. Coronavirus vaccine tracker. 2020. Available from: https://www.nytimes.com/interactive/2020/science/ coronavirus-vaccine-tracker.html. Accessed 30 Dec 2021.

2. Berliner U. Should the government pay people to get vaccinated? Some economists think so. NPR. 2021. Available from: https://www.npr.org/2021/01/13/955594105/should-the-gover nment-pay-people-to-get-vaccinated-some-economists-think-so. Accessed 20 Feb 2021.

3. Riley J. The best herd immunity money can buy. Wall Street J. 2020. Available from: https://www.wsj.com/articles/the-bestherd-immunity-money-can-buy-11607469746. Accessed 30 Dec 2020.

4. Litan R. Want herd immunity? Pay people to take the vaccine. Brookings. 2020. Available from: https://www.brookings.edu/ opinions/want-herd-immunity-pay-people-to-take-the-vaccine/. Accessed 20 Feb 2021.

5. McNeil D. How much herd immunity is enough? New York Times. 2021. Available from: https://www.nytimes.com/2020/ 12/24/health/herd-immunity-covid-coronavirus.html. Accessed 30 Dec 2021.

6. Cutter C, Krouse S. Why many bosses won't require workers to get the Covid-19 vaccine. Wall Street J. 2020. Available from: https://www.wsj.com/articles/bosses-balk-at-requiring-covid19-vaccine-for-workers-11608561398. Accessed 31 Dec 2021.

7. McNeil SA, Shinde V, Andrew M, Hatchette TF, Leblanc J, Ambrose A, et al. Interim estimates of 2013/14 influenza clinical severity and vaccine effectiveness in the prevention of. Euro Surveill. 2014;19:1-6.

8. Hou Z, Chang J, Yue D, Fang H, Meng Q, Zhang Y. Determinants of willingness to pay for self-paid vaccines in China. Vaccine. 2014;32:4471-7. https://doi.org/10.1016/j.vaccine.2014. 06.047 .

9. Hadisoemarto PF, Castro MC. Public acceptance and willingnessto-pay for a future dengue vaccine: a community-based survey in Bandung, Indonesia. PLoS Negl Trop Dis. 2013;7:e2427.

10. Lee JS, Mogasale V, Lim JK, Carabali M, Sirivichayakul C, Anh DD, et al. A multi-country study of the household willingnessto-pay for dengue vaccines: household surveys in Vietnam, Thailand, and Colombia. PLoS Negl Trop Dis. 2015;9:1-15.

11. Cerda AA, García LY, Albornoz DV. Parents willingness to pay for a human papillomavirus vaccine to protect their adolescent daughters, Maule Region, Chile. Salud Publica Mex. 2014;56:48-55.

12. Berghea F, Berghea CE, Abobului M, Vlad VM. Willingness to Pay for a for a Potential Vaccine Against SARSCoV-2/COVID19 Among Adult Persons. 2020.

13. Harapan H, Wagner AL, Yufika A, Winardi W, Anwar S, Gan AK, et al. Acceptance of a COVID-19 vaccine in southeast Asia: a cross-sectional study in Indonesia. Front Public Health. 2020;8:381.

14. Wong LP, Alias H, Wong P-F, Lee HY, AbuBakar S. The use of the health belief model to assess predictors of intent to receive the COVID-19 vaccine and willingness to pay. Hum Vaccin Immunother. 2020;16(9):2204-14.

15. Sarasty O, Carpio CE, Hudson D, Guerrero-Ochoa PA, Borja I. The demand for a COVID-19 vaccine in Ecuador. Vaccine. 2020;38:8090-8.

16. Cerda AA, García LY. Willingness to pay for a COVID-19 vaccine. Appl Health Econ Health Policy. 2021;19(3):343-51. 
17. García LY, Cerda AA. Contingent assessment of the COVID-19 vaccine. Vaccine. 2020;38:5424-9.

18. Carpio CE, Sarasty O, Hudson D, Macharia A, Shibia M. The demand for a COVID-19 vaccine in Kenya. Hum Vaccin Immunother. 2021;17(10):3463-71.

19. Bronchetti ET, Huffman DB, Magenheim E. Attention, intentions, and follow-through in preventive health behavior: field experimental evidence on flu vaccination. J Econ Behav Organ. 2015;116:270-91.

20. Robertson C, Scheitrum D, Schaefer A, Malone T, McFadden BR, Messer KD, et al. Paying Americans to take the vaccine-would it help or backfire? J Law Biosci [Internet]. 2021;8. https://acade mic.oup.com/jlb/article/doi/10.1093/jlb/lsab027/6352998.

21. Yue M, Wang Y, Low CK, Yoong JS, Cook AR. Optimal design of population-level financial incentives of influenza vaccination for the elderly. Value Health. 2020;23:200-8.

22. Sprengholz P, Eitze S, Felgendreff L, Korn L, Betsch C. Money is not everything: experimental evidence that payments do not increase willingness to be vaccinated against COVID-19. J Med Ethics. 2021;47(8):547-8.

23. Our World in Data. Coronavirus (COVID-19) vaccinations. 2021. Available from: https://ourworldindata.org/covid-vaccinations? country=USA\%0A. https://coronavirus.jhu.edu/us-map\%0A. Accessed 27 Aug 2021.

24. The New York Times. Coronavirus in the US: latest map and case count. New York Times. 2021. Available from: https://www.nytim es.com/interactive/2021/us/covid-cases.html. Accessed 27 Aug 2021.

25. U.S. Department of Health and Human Services Food and Drug Administration. Development and licensure of vaccines to prevent COVID-19: guidance for industry. 2020. Available from: https:// www.fda.gov/media/139638/download. Accessed 30 Dec 2021.

26. Cerda AA, García LY. Hesitation and refusal factors in individuals' decision-making processes regarding a coronavirus disease 2019 vaccination. Front Public Health. 2021;9:626852.

27. Kanninen BJ. Design of sequential experiments for contingent valuation studies. J Environ Econ Manag. 1993;25:S1-11.

28. Cao S. COVID-19 vaccine prices revealed from Pfizer, Moderna, and AstraZeneca. Observer. 2020. Available from: https://obser ver.com/2020/11/covid19-vaccine-price-pfizer-moderna-astra zeneca-oxford/. Accessed 31 Dec 2020.

29. APhA. Reimbursement for Administration of COVID-19 Vaccine(s)_What We Know. Am. Pharm. Assoc. 2021.

30. SAS. Cary: SAS Institute Inc.; 2012.

31. MATLAB. Natick: The Mathworks Inc.; 2018.

32. Hanemann M, Kanninen B. The statistical analysis of discreteresponse CV data. Valuing environmental preferences. New York: Oxford University Press; 2001. p. 302-441.

33. Turnbull BW. The empirical distribution function with arbitrarily grouped, censored and truncated data. J R Stat Soc Ser B. 1976;38:290-5. https://doi.org/10.1111/j.2517-6161.1976.tb015 97.x.

34. Greene WH. Econometric analysis. 8th ed. New York: Pearson Education, Inc.; 2018

35. United States Census Bureau. Selected economic characteristics. 2021. Available from: https://data.census.gov/cedsci/table?q= UnitedStates \& $g=0100000$ US\&tid=ACSDP1Y2019.DP03\&hideP review $=$ true. Accessed 24 Sep 2021.
36. United States Census Bureau. Selected economic characteristics. 2021.

37. Kaiser Family Foundation. KFF Health Tracking Poll/KFF COVID-19 vaccine monitor. Kaiser Family Foundation; 2020. p. $1-24$.

38. Szilagyi PG, Thomas K, Shah MD, Vizueta N, Cui Y, Vangala $\mathrm{S}$, et al. National trends in the US public's likelihood of getting a COVID-19 vaccine: April 1 to December 8, 2020. JAMA. 2021;325:396-8.

39. Lin C, Tu P, Beitsch LM. Confidence and receptivity for COVID19 vaccines: a rapid systematic review. Vaccines. 2021;9:16.

40. Jecker NS. What money can't buy: an argument against paying people to get vaccinated. J Med Ethics. 2021. https://doi.org/10. 1136/medethics-2021-107235.

41. Gersen J. Should the government impose a national vaccination mandate?. New Yorker. 2021. Available from: https://www.newyo rker.com/news/our-columnists/should-the-government-impose-anational-vaccination-mandate. Accessed 27 Aug 2021.

42. Carpio CE, Sarasty O, Hudson D, Macharia A, Shibia M. The demand for a COVID-19 vaccine in Africa: evidence from Kenya. 2020. Available from: https://www.researchgate.net/publication/ 345177667_The_demand_for_a_COVID-19_vaccine_in_Africa_ Evidence_from_Kenya. Accessed 25 Sep 2021.

43. Schwarzinger M, Watson V, Arwidson P, Alla F, Luchini S. COVID-19 vaccine hesitancy in a representative working-age population in France: a survey experiment based on vaccine characteristics. Lancet Public Heal. 2021.

44. Borriello A, Master D, Pellegrini A, Rose JM. Preferences for a COVID-19 vaccine in Australia. Vaccine. 2021;39:473-9.

45. Dong D, Xu RH, Wong EL, Hung C, Feng D, Feng Z, et al. Public preference for COVID-19 vaccines in China: a discrete choice experiment. Health Expect. 2020;23:1543-78.

46. Islam F, Agarwalla R, Panda M, Alvi Y, Singh V, Debroy A, et al. Assessment of the knowledge, preferences and concern regarding the prospective COVID-19 vaccine among adults residing in New Delhi, India: a cross-sectional study. J Family Med Prim Care. 2021;10(6):2369-75.

47. García LY, Cerda AA. Acceptance of a COVID-19 vaccine: a multifactorial consideration. Vaccine. 2020;38:7587.

48. Sprengholz P, Eitze S, Korn L, Siegers R, Betsch C. The power of choice: experimental evidence that freedom to choose a vaccine against COVID-19 improves willingness to be vaccinated. Eur J Intern Med. 2021;87:106-8.

49. Irfan U. Why comparing Covid-19 vaccine efficacy numbers can be misleading [Internet]. Vox. 2021 [cited 2021 Mar 5]. https:// www.vox.com/22311625/covid-19-vaccine-efficacy-johnsonmoderna-pfizer.

50. Khubchandani J, Sharma S, Price JH, Wiblishauser MJ, Sharma M, Webb FJ. COVID-19 vaccination hesitancy in the United States: a rapid national assessment. J Community Health. 2021;46:270-7.

51. Callaghan T, Moghtaderi A, Lueck JA, Hotez P, Strych U, Dor A, et al. Correlates and disparities of intention to vaccinate against COVID-19. Soc Sci Med. 2021. https://doi.org/10.1016/j.socsc imed.2020.113638.

52. Tentori K, Passerini A, Timberlake B, Pighin S. The misunderstanding of vaccine efficacy. Soc Sci Med. 2021;114273. 